\title{
The use and limits of various methods of sampling and interpretation of benthic macro-invertebrates
}

\author{
Antony DAVIES \\ 4 Berry Lane, Godinanchester, Cambridgeshire, PE29 2LA UK
}

\begin{abstract}
This paper attempts to provide an overview of the present state of the art of biological sampling of aquatic benthic macro-invertebrates as reflected in the international standard methods of the International Standards Organisation (ISO) and the European Standards Organisation (CEN). Also of importance are guideline standards which assist in the standardisation of the interpretation and presentation of the biological data. The importance of standardising methods of sampling aquatic habitats has been recently recognised by the European Union by the inclusion of these standards as a mandatory requirement within the Framework Directive (2000/60 EC European Parliament and Council) for the protection of inland surface waters. Adherence to these standards of sampling by member countries ensures that the biological survey data is comparable throughout the Union and can be assessed as an improvement, deterioration or stable biological quality at agreed survey sites.
\end{abstract}

Key words: International standards, benthic macro-invertebrates, sampling methods, interpretation, presentation of biological data

\section{INTRODUCTION}

This presentation has been prompted by the recognition that there are many modern-day biologists specialising in the flora and fauna of rivers and other surface waters who have had no practical experience or training in obtaining biological samples. Indeed they are almost exclusively pre-occupied with computerising past data. without understanding the reasons why the samples were taken in the first place. This leads to not only the misapplication of the data but inevitably its misinterpretation.

It is considered most important to recognise that no one sampling method will provide enough data to reflect the actual biological community which exists in the area sampled. The use of the kick-net method used to obtain samples of the macro-invertebrate riffle type habitat communities cannot be used to obtain samples in deep slow flowing rivers or lake waters and different sampling methods have to be designed for this purpose.

This paper attempts an overview of the present state of the art of biological sampling as reflected in the national and international standardisation of methods of sampling freshwater macro-invertebrate communities. It is emphasised that biological data for any given aquatic habitat does not of itself define that habitat; many other factors must be taken into account before even a basic definition of the habitat can be obtained. Among the more important are the hydrological and hydromorphological variables which include flow rate, turbulence, rugosity river channel type and catchment characteristics. Physico chemical factors are also important in particular, temperature, $\mathrm{pH}$ (acidification status), oxygenation, salinity and presence of pollutants. Other biological components of the habitat must also be considered such as macrophytes, fish and diatom populations etc.
This has recently been recognised in the publication of a framework directive for the protection of inland surface waters, transitional, coastal and groundwater refer Directive 2000/60/EC European Parliament and Council. Under 1.3.6 page.L327/S7 Standards for the Monitoring of Quality Elements. In this directive member countries of the Europe, an Union are obliged to conform to the international or national standards to ensure: "the provision of data is of an equivalent scientific quality and comparability". Biological comparability is regarded as essential for progress to be made in the understanding of biological communities owing to the continual variability of not only the type and density of the organisms but also of the changing physical and chemical environment of any given habitat with time.

\section{STANDARDISED METHODS OF MACRO- INVERTEBRATE SAMPLING}

The use of macro-invertebrates (defined as invertebrates of size greater than $0.5 \mathrm{~mm}$ ) as indicators of river quality have been used for at least the past fifty years. To begin with it was thought that the presence, or absence, of a particular species/family/class etc. of macroinvertebrate organism could be used to characterise a pollutant in a river water. This concept has however been shown in practise to be unreliable and is no longer used in river management being replaced by biological quality of rivers and of other surface waters, which encompasses not only macro-invertebrates but many other facets of river quality. The introduction of the computer into the biological sciences has enabled a considerable advance in the application of statistics to biological data. This has resulted in many different methods of presenting biological data which take the form of biotic indices. 
APPENDIX 1

Standards for the monitoring of quality elements

(EC Framework Directive 22.12.2000)

From: Official journal of che European communities

Habitat and species protection are

Bodies of water forming these areas shall be included within the operational monitoring programme referred to above where, on the basis of the impact assessment and the surveillance monitoring, they are identifted as being at risk of failing to meet their environmental objectives under Article 4. Monitoring shall be carried out to assess che magnitude and impact of all relevant significant pressures on these bodies and, where necessary, to assess changes in che status of such bodies resulting from che programmes of measures. Monitoting shall continue until che areas satisfy the water-related requirements of the legislation under which they are designated and meet their objectives under Article 4.

1.3.6. Standards for monitoring of quality elements

Methods used for the monitoring of type parameters shall conform to the international standards listed below or such other national or international standards which will ensure the provision of data of an equivalent scientific quality and comparability.

Macro-invertebrate sampling

ISO 5667-3:1995

EN 27828:1994

EN 28265:1994

EN ISO 9391:1995

EN ISO 8689-1:1999

EN ISO 8689-2:1999

Water quality - Sampling - Part 3: Guidance on che preservation and handling of samples.

Water quality - Methods for biological sampling - Guidance on hand-net sampling of benthic macro-invertebrates.

Water quality - Methods of biological sampling - Guidance on che design and use of quantitative samplers for benthic macro-invertebrates on stony substrata in shallow waters.

Water quality - Sampling in deep waters for macroinvertebrates - Guidance on che use of colonisation, qualitative and quantitative samplers.

Biological classification of rivers PART 1.- Guidance on the interpretation of biological quality data from surveys of benthic macro-invertebrates in running waters.

Biological classification of rivers PART 11 - Guidance on the presentation of biological quality data from surveys of benthic macro-invertebrates in running waters.

Macrophyte sampling

Relevant CEN ISO standards when developed

Fish sampling

Relevant CEN/ISO standards when developed

Diatom sampling

Relevant CEN/ISO standards when developed

Standards for physico-chemical parameters

Any relevant CEN/ISO standards

Standards for hydromorphological parameters

Any relevant CEN/ISO standards 
In general the standardisation of biological methods of sampling involves a definition of procedure, interpretation of the data and its presentation, this later being referred to as biological classification.

At present three biological sampling categories have been standardised each dealing with the sampling of benthic macro-invertebrates in two aquatic environments of flowing water, shallow and deep water. Two international standards dealing with the interpretation and presentation of data and one standard for the preservation and handling of samples.

The two international standards organisations involved are the International Standards Organisation (ISO) which involves most countries of the World and the European Standards Organisation (CEN) which is very closely associated with the European Union (EU). In 1995 the European Commission recognised the importance of international standards for the implementation of environmental directives and was instrumental in establishing a CEN technical Committee (TC) called CEN TC 230 Water Quality. This TC is responsible for deriving standards for the measurement of the chemical, biological and microbiological quality of water. To start with many of the necessary standards were not available within CEN and it was necessary to adopt with minor modifications existing ISO standards. Indeed it is now common practice for CEN or ISO to adopt and develop mutually acceptable standards using the Vienna Agreement an administrative procedure called parallel voting. For example the standard relating to the sampling for macro-invertebrates in deep water, EN ISO 9391:1995 was developed in ISO committees and adopted by CEN for specific European application within the European Union.

It should be noted that if a CEN standard is referred to in directives of the European Union its use becomes largely mandatory and replaces any national standard of a member country of the European Union relating to the same subject. This ensures that reports on the biological quality of rivers at specifically chosen survey sites, for example, throughout the countries of the EU may be compared and intercalibrated trends in biological quality can be identified as improving, deteriorating or unaltered.

\subsection{Hand net sampling of aquatic benthic macro- invertebrates, ISO 7828:1985; EN27828:1994}

This method of sampling a wide variety of shallow waters, depth limit $1.5 \mathrm{~m}$, has been used by hydrobiologists for very many years and during this time has proven to give consistent results when used repeatedly at a given site. The hand-net or sometimes referred to a the kick-net method of sampling is not quantitative but may be validated using quadrat samplers. It has been shown that the correlation coefficient between the two sampling methods based on numbers of taxa collected is highly significant at $\mathrm{r}=0.98$, refer Appendix I. The primary objective in using this method should be to obtain as comprehensive a list of taxa as possible.

The habitats it is possible to sample using the handnet is largely defined by its accessibility whether river or stream ponds or estuaries. The qualitative data obtained defines presence/absence/diversity and relative abundance of taxa; the greater the sampling effort the more reliable or representative the result. Depending on the habitat, such as flow rate, degree of vegetative cover, type of substrate and water depth. The following procedures may be appropriate hand sampling very shallow water, kick-net for deeper water. For slow flowing or static waters flow through the net may be enhanced by pushing the net repeatedly through the bottom silts but grabs, dredges, corers etc. may also be used.

To obtain an indication of the relative abundance of taxa fixed time of sampling or defined sample area may be used, for example, hand sampling 10 min, kick-net 2$5 \mathrm{~min}$. Due to the inherent subjective nature in the use of the hand-net it is advisable to ensure as far as possible that the same person carries out the sampling repeats at the same sampling locations. Even so the conditions of the habitat may vary considerably from one visit to next; due to changes in current velocity, depth, water temperature, time of year, etc.

The most important aspect of the hand-net sampler is that in one form or another it has been and is being used extensively throughout the World to obtain data on which to base a biological classification of surface waters. It is relatively simple to use and to train operatives in the basic identification of classes and families of macro-invertebrates.

\subsection{Quantitative samplers for benthic macro- invertebrates on stony substrata in shallow freshwaters, ISO 8265: 1988 (E), EN 28265 :1994}

The application of these quantitative samplers is dictated by accessibility and a sampling site in which current velocities are in excess of $0.1 \mathrm{~m} \mathrm{~s}^{-1}$ and a depth of less than $0.5 \mathrm{~m}$. These samplers are known as quadrat samplers in which the bed of a water body is isolated and the disturbance of the substrate releases the macroinvertebrates which are carried into a net located downstream but an integral part of the sampler by the water current. It is usual for the area of substrate sampled to approximate $0.1 \mathrm{~m}^{-2}$. The selection of the net size depends on the purpose for sampling.

The quadrat sampler is also known as a Surber sampler of which there exists several designs but all have the same basic construction. The application of the Surber is ideal for obtaining representative samples of biological communities in riffle habitats. Another variation on the same theme of standardising sample substrate area is the cylinder sampler which is driven into the substrate using a rotary motion to a depth of $70 \mathrm{~mm}$. 


\subsection{Sampling in deep waters for macro-invertebrates. Guidance on the use of colonisation, qualitative and quantitative samplers. ISO 9391:1993; EN ISO 9391:1995}

Colonisation samplers were designed to provide a collection of macro-invertebrates capable of living and indeed colonising an artificial substrate and therefore reflecting directly the water quality of the sample site. This method does not represent the fauna of the naturally occurring macro-invertebrate population, which may be restricted by physical factors unrelated to water quality. In upland rivers riffles are readily available enabling a comparison to be made of the biological quality between different sites but of similar biotope. In lowland rivers it is frequently impossible to obtain similar habitats owing to large variations in river flow rate, substrate stability, deoxygenation, sediment transport, etc. The use of an artificial substrate for colonisation increases the confidence for comparison of what such relatively unstable habitats can sustain in terms of water quality by providing a standardised substratum.

The standard colonisation media may be 40 pieces of $4 \mathrm{~cm}$ biological filter media placed in a coarse mesh polyamide bag or more satisfactorily a standard colonisation unit made of 14 pieces of cylindrical-type plastic biological filter media. The colonisation sampler should be placed in the main flow of the river and submersed for four to six weeks with a minimum of three replicates for each sampling site. The number of taxa is then the total of all the samples. The contents of the sampler should be sieved thruogh size $4 \mathrm{~mm}$ and then washed into a fine retaining sieve of $250 \mu \mathrm{m}$. The removal of several organism from the colonisation media may present some difficulties but the use of spraying with a water jet, forceps, shaking or immersion in $0.4 \% \mathrm{v} / \mathrm{v}$ Formaldehyde or warm water should suffice.

In the event that the location is suitable for actual sampling there exists three basic objectives in deep water sampling:

- to obtain a list of taxa when relative abundance is not needed the minimum requirement is to obtain samples of all types of micro-habitat on the river bed. For this purpose a dredge would be adequate;

- to obtain the relative abundance of an organism, for this it is necessary to use a quantitative sampler so that the samples of substrate are taken in a reproducible manner; a qualitative sampler would introduce a large operator error. An example of quantitative deep water samplers would be the air-lift sampler and the pole operated Berg-Eckman grab;

- to obtain biomass per unit area or the density of organisms only, quantitative samplers can be used for this type of sampling for example, the air-lift, corers and certain grabs. Such exercises require many replicate samples to be taken for each habitat.

These samplers are for use in rivers of depth greater than $1 \mathrm{~m}$ over various substrates ranging from mud de- posits to gravel with stone size less than $15 \mathrm{~cm}$ and not in rivers with very high flow rates.

\section{INTERPRETATION}

\subsection{Biological classification of rivers}

Part I. Guidance on the interpretation of the biological quality data from surveys of benthic macro-invertebrates. EN ISO 8689-1:2000

The importance of this document is such that it included in its entirety in Appendix II of this paper as it represents the present state of thinking within the international "community" of hydrobiologists.

In summary the following points of fundamental importance are made in relation to the interpretation of aquatic biological data.

- The primary objective of biological surveys is to quantify the difference between naturally occurring stress, such as yearly flood events and man made stresses which may originate from organic pollution, in terms of a measured alteration in the biological quality of the sampling site. Where man made stress is considered to be absent the biological state is defined as the expected natural community.

- To evaluate the stress from survey data of benthic macro-invertebrate communities in running water the observed data is compared to reference data, the expected natural community, which is what would be expected in the absence of man made stress. The biological classification is based on the disparity of observed and reference data.

- To measure the level of a particular stress a biological index or biological score system is used, initially based on family level identification, if higher resolution is required genus or even species level may be justified. The most commonly used stress index using benthic macro-invertebrates relates to organic pollution and many different score systems have been devised. The changes in benthic macro-invertebrate populations are also being used to assess stresses associated with current velocity, substrate stability and levels of eutrophication.

\subsection{Water quality-Biological classification of rivers}

Part II Guidance on the presentation of biological quality data from survey of benthic macro-invertebrates, EN ISO 8689 2: 2000

Part II Should be regarded as an extension of Part I in which the biological quality defined from good to bad is further refined into colour bands suitable for presentation as colour coded maps and from which it is possible to obtain a biological quality overview as it relates to benthic macro-invertebrates in running waters.

It is important to note that it is not the responsibility of standards organisations to set standards of compli- 


\section{APPENDIX II}

\section{Normative references to international publications with their relevant European publications}

This European Standard incorporates by dated or undated reference, provisions from other publications. These normative references are cited at the appropriate places in the text and the publications are listed hereafter. For dated references, subsequent amendments to or revisions of any of these publications apply to this European Standard only when incorporated in it by amendment or revision. For undated references the latest edition of the publication referred to applies.

\begin{tabular}{|c|c|c|c|c|}
\hline Publication & Year & Title & $\mathrm{EN}$ & Year \\
\hline ISO5667-3 & 1994 & $\begin{array}{l}\text { Water quality - Sampling - Part 3: Guidance on the } \\
\text { preservation and handling of samples }\end{array}$ & EN ISO 5667-3 & 1995 \\
\hline ISO7828 & 1985 & $\begin{array}{l}\text { Water quality - Methods of biologica] sampling; } \\
\text { Guidance on hand-net sampling of aquatic benthic } \\
\text { macro-invertebrates }\end{array}$ & EN 27828 & 1994 \\
\hline ISO8265 & 1988 & $\begin{array}{l}\text { Design and use of quantitative samplers for benthic } \\
\text { macro-invertebrates on stony substrata in shallow } \\
\text { freshwaters }\end{array}$ & EN 28265 & 1994 \\
\hline ISO/DIS 8689-1 & 1998 & $\begin{array}{l}\text { Water quality - Biological classification of rivers - } \\
\text { Part 1: Guidance on the interpretation of biological } \\
\text { quality data from surveys of benthic macro- } \\
\text { invertebrates in running waters }\end{array}$ & prEN ISO 8689-2 & 1998 \\
\hline ISO9391 & 1993 & $\begin{array}{l}\text { Water quality - Sampling in deep waters for macro- } \\
\text { invertebrates - Guidance on the use of colonization, } \\
\text { qualitative and quantitative samplers }\end{array}$ & EN ISO 9391 & 1995 \\
\hline
\end{tabular}

ance this is entirely the responsibility of the regulatory authorities, for example the European Commission.

The following observations are made.

- For the purposes of presentation water courses should be divided into reaches each having a consistent biological quality. A reach is defined as a length of watercourse forming a major sub-division of a river catchment (basin) and possessing defined, physical, chemical or hydrological characteristics which distinguish it from the same watercourse both upstream and downstream. This definition can therefore be sensibly applied to macro-invertebrate quality.

- The colours chosen are blue high biological quality, green good, yellow moderate, red poor, brown bad and black absence of indicator groups of benthic macro-invertebrate organisms.

It should be noted that Water quality-Biological classification of rivers - Part III Guidance on the definition of biological quality boundaries is being considered within CEN TC 230 WG2 TG 1 but progress is slow, owing to the rejection of the European Commission of the need for such guidance as it is considered to violate the responsibility of the Commission in defining standards of compliance which is outside the scope of a
CEN committee. This is accepted but without Part III it will not be possible to better define the transition from one biological quality colour boundary into another and there will be an inevitable loss of effective comparisons between the rivers of member countries of the European Union in terms of their quality of the macro-invertebrate benthos.

\section{CONCLUSIONS}

Like all international standards, those discussed in this paper will be subject to revision every five years, sometimes it is found unnecessary but if regulations change or as with the hand-net sampling method ISO 7828 there has been a significant increase in areas of application of the sampling method these have to added and the standard modified to accommodate them.

Many aspects of the art of assessing the viability, diversity and success of macro-invertebrate communities obtained from the various methods of sampling identification and analysis have of necessity been omitted.

The in-word at present used extensively in the field of river water science is TYPOLOGY. This purports to provide the basis for the standardisation and interpretation of all biological survey data. Typology is defined by the physical characteristics of a river channel: its hydromorphology. The objective of this is to enable, for 
example, meaningful comparisons to be made between standardised river types as defined by their physical configurations and to extrapolate these as representative of the various ecologies which such river channels are known to support. This is of course should not be used as it is an over simplification of the aquatic habitat in which the biological component of the ecology is minimised or excluded. The use of hydrological characteristics to define a macro-invertebrate environment is to be applauded and encouraged as this aspect of hydrobiology has been sadly neglected in the past. However, this encouragement should not go so far as to support the concept that these hydrological parameters can be used to replace the work of the biologist and also the chemist in defining the ecological state of a given environment.
The biologist, chemist, hydrologist etc. all have a part to play in providing data from which to obtain an over view of the ecological quality of a given environment. For example, the biological data can provide an insight into the present and past biological quality of a river water but cannot identify the cause only the effect. The chemical quality of the water can frequently provide information on the cause of the biological response while the hydrologist can provide flow rate data which again can effect biological quality.

The need to obtain value for money by applying statistics or administrative procedures to scientific survey work is a very real danger which often results in oversimplification by unjustified assumptions which have not been scientifically verified. 